OPEN ACCESS

Edited by:

Rachel Gjelsvik Tiller,

SINTEF, Norway

Reviewed by:

Jordan Feekings,

Technical University of Denmark,

Denmark

Stephen Eayrs,

Smart Fishing Consulting, Australia

*Correspondence:

Robert Murphy Jr.

rdmurphy@alaskapacific.edu

Specialty section:

This article was submitted to

Marine Fisheries, Aquaculture

and Living Resources,

a section of the journal

Frontiers in Marine Science

Received: 22 October 2021

Accepted: 24 January 2022

Published: 24 February 2022

Citation:

Murphy $R \mathrm{Jr}$, Yochum $\mathrm{N}$, Wolf $\mathrm{N}$

Kroska AC and Harris BP (2022)

Barriers to Achieving Conservation

Engineering Goals in Commercial

Trawl Fisheries.

Front. Mar. Sci. 9:800176.

doi: 10.3389/fmars.2022.800176

\section{Barriers to Achieving Conservation Engineering Goals in Commercial Trawl Fisheries}

\author{
Robert Murphy Jr. ${ }^{1 *}$, Noëlle Yochum ${ }^{2}$, Nathan Wolf ${ }^{1}$, Anita C. Kroska ${ }^{1}$ and \\ Bradley P. Harris ${ }^{1}$
}

${ }^{1}$ Fisheries, Aquatic Science and Technology Laboratory, Alaska Pacific University, Anchorage, AK, United States, ${ }^{2}$ Midwater Assessment and Conservation Engineering Program, Resource Assessment and Conservation Engineering Division, National Oceanic and Atmospheric Administration, National Marine Fisheries Service, Alaska Fisheries Science Center, Seattle, WA, United States

The advancement of conservation practices in global trawl fisheries has been impeded in part by a lack of a collective understanding of the most relevant and broadscale knowledge-needs, along with the identification of potential barriers to addressing these knowledge-needs. Using both an online survey and an in-person workshop, we engaged a diversity of fishing industry stakeholders including scientists, technology companies, trawl net makers, and fishermen working with North Pacific, United States, trawl fisheries to identify and prioritize areas in which further knowledge is required for successful implementation of conservation engineering practices. In addition, we identified barriers to addressing these knowledge-needs. Knowledge-needs related to fishing gear performance were identified among the top priorities, including several areas targeted at improving fishing efficiency that could further advance the sustainability of well-managed trawl fisheries. To better understand the composition and behavior of target versus non-target catch, workshop participants identified the importance of closing data and technology gaps. This highlights areas for potential collaboration between fishermen, researchers, and technology companies to address research prioritized by the end-user. Further, results from the workshop emphasized a need for industry-driven training and workshops focused on elevating fishermen skill for newer entrants through peer-learning and knowledge-sharing to achieve objectives like better non-target avoidance and increased fishing efficiency of the target species. Addressing these prioritized knowledge-needs, by first working toward overcoming the industry-identified barriers, may aid in increasing uptake of conservation practices, thereby contributing to the long-term sustainability of these fisheries and associated social-ecological systems.

Keywords: commercial fishing, fishery management, conservation engineering, human dimensions, stakeholder participation

\section{INTRODUCTION}

Bottom and pelagic trawl fisheries account for over one-third of the global annual fish production by biomass (Pauly et al., 2020). While this reflects a significant contribution to food security goals, trawl fisheries receive considerable attention because of their potential impacts on marine ecosystems (e.g., Hutchings, 1990; Clark et al., 2016). Trawling can result in discard mortality (i.e., 
bycatch) (Kennelly, 1995; Finkbeiner et al., 2011) and can negatively impact benthic habitats and communities when ground-gear contacts the seafloor (Althaus et al., 2009; Grabowski et al., 2014). However, amendments to fishing gear and practices through conservation engineering approaches (i.e., the development, modification, and evaluation of fishing gear, fishing techniques, and fishing-related technology to mitigate incidental effects of fishing) can improve the sustainability of trawling practices by lowering bycatch rates and minimizing benthic impacts (Broadhurst et al., 2015; Stram and Ianelli, 2015; Food and Agriculture Organization [FAO], 2020). For example, bycatch reduction devices aim to increase trawl selectivity by directing non-target catch away from or through fishing nets by taking advantage of differences in target versus non-target species morphology, behavior, and stimuli response (Brewer et al., 1998). Similarly, improvements in catch efficiency can result in reduced effort, and therefore, lead to fewer seafloor-gear contact events and reduced fuel usage, thereby reducing greenhouse gas emissions and overall environmental impact (Murphy et al., 2021). These improvements could manifest through several aspects of trawling, such as reduced benthic interaction, lower bycatch, decreased discard mortality, and decreased gear loss (i.e., derelict or ghost gear, marine debris).

Implementation of these innovative fishing strategies and technologies by fishermen has been limited despite research efforts in conservation engineering. This is potentially due to incorrect incentives, or regulatory, industrial, environmental, and financial constraints (e.g., Cunningham et al., 2016; Eayrs and Pol, 2019; Feekings et al., 2019; Murphy et al., 2021). The motivations of industry could also affect voluntary uptake of innovative approaches, as well as engagement with industry in the development and evaluation of conservation engineering projects (Eayrs and Pol, 2019). Given this diversity of potential impediments, developing and implementing conservation-focused innovations to fishing practices require active collaboration with fishermen, fishery managers, and other stakeholders in a bottom-up fashion that helps facilitate the feasibility of developments (Decker et al., 1996; Catchpole and Gray, 2010; Armstrong et al., 2013; Feekings et al., 2019).

While active collaboration with stakeholders, including fishermen, is not a new practice (e.g., Berkes, 2009; Wilberg et al., 2009; Yochum et al., 2011; Hegger and Dieperink, 2014), collaborations specifically focused on impediments to the implementation of conservation strategies are less common. In a study aimed at identifying knowledge-needs to reduce the habitat impacts of bottom trawling while maintaining sustainable fishing practices, Kaiser et al. (2016) conducted a multi-step process of discussions and voting with representatives from fisheries stakeholder groups distributed across 11 countries. The authors used these stakeholder-driven prioritizations to develop a list of questions to support a transition toward the adoption of best practices for limiting ecological effects to the seabed from trawl fishing. However, Kaiser et al.'s (2016) study was strictly intended to provide directions for future research and did not seek to examine potential barriers to answering the questions. Identifying these barriers could enable researchers, managers, and practitioners to deploy resources more efficiently.
Using similar strategies to Kaiser et al. (2016), we conducted a multi-step stakeholder engagement study to identify knowledgeneeds for conservation engineering research. Additionally, we extended previous efforts by identifying barriers to addressing these needs for a diverse range of fisheries stakeholders in the North Pacific, United States. While we recognize that successful implementation of new conservation engineering strategies will require more than the identification of knowledge-needs and barriers (e.g., psychological factors may limit the uptake of new strategies; Eayrs and Pol, 2019), this is a critical first step toward promoting increasingly sustainable trawl fisheries. Using expert discussions, online surveys, and an in-person workshop, we worked with scientists, technology companies, trawl net makers, and fishermen from several North Pacific trawl fisheries to answer two primary questions: (1) What outstanding conservation engineering questions (i.e., knowledge-needs) are most important to the trawl fishing industry in the North Pacific? (2) What are the barriers to answering these knowledgeneeds? We envision that answering these questions will aid in the long-term sustainability of these fisheries and associated social-ecological systems by calling attention to where increased effort is needed based on industry perspectives. More broadly, understanding barriers in fisheries contributes to our collective efforts toward global fisheries sustainability through increased collaboration with fishermen and their uptake of conservation engineering solutions.

\section{MATERIALS AND METHODS}

All methods and survey tools were approved by the Alaska Pacific University Institutional Review Board prior to project initiation, and all surveys included a participant consent form.

\section{Survey Participants}

Participants for this study were associated with the Fisheries Innovation for Sustainable Harvest (F.I.S.H.) Workshop held at the National Oceanic and Atmospheric Administration (NOAA) offices in Seattle, WA in 2019, with concurrent remote sessions in Newport, Oregon, and Kodiak, Alaska. While the F.I.S.H. Workshop aims to attract diverse fishery participants, the sheer geographic scope and breadth of fisheries across the North Pacific prohibit a truly representative sample of fishery participants from attending. However, participants of the workshop and our study represented different regional fisheries (e.g., Gulf of Alaska, $G O A$; Bering Sea/Aleutian Islands, BSAI), different sizes and types of vessels (e.g., catcher vessel, catcher processor), and in their relationships to the fisheries (e.g., net manufacturers, fishing company managers, captains, crew, fishing technology company representatives) thereby reducing biases associated with focusing on only a few sectors or stakeholder groups. As such, the results of our study should be interpreted in light of the types of fishery participants present for the workshop. Moreover, the goal of the workshop was to learn and evaluate challenges in fisheries science, management, and fishing practices. Given its focus, the F.I.S.H. workshop presented an ideal opportunity to gather information on conservation engineering knowledge-needs in 
these fisheries and better understand the barriers preventing progress in addressing those needs.

\section{Knowledge-Need Identification}

Unlike Kaiser et al. (2016), who established knowledge-needs for conservation engineering at an in-person meeting, we employed an online survey using the Qualtrics Survey Software Research Suite (Figure 1). The survey was developed in conjunction with the F.I.S.H. Workshop steering committee (scientists, trawl gear manufacturers, fishermen, and fishing industry representatives) via discussions about the objectives perceived to be most important to their respective fisheries. The survey contained questions on 30 separate conservation engineering knowledgeneeds organized into four broad categories: (1) monitoring of the trawl gear and catch while fishing (e.g., net mensuration); (2) understanding fish behavior as it relates to fishing (e.g., catchability, selectivity); (3) understanding the performance of gear and fishing practices (e.g., catch-per-unit-effort); and (4) answering applied questions about the fishing industry that are related to conservation engineering (Table $\mathbf{1}$ and Figure 1). Included in these knowledge-needs were questions related to safety, acknowledging the close relationship between safety and fishing gear design and use. Several knowledge-needs were closely based on items identified in Kaiser et al. (2016). As well as assisting with survey design, the F.I.S.H. Workshop steering committee provided guidance to ensure question comprehension and topic relevancy.

A link to the online survey was sent on December 3rd, 2019 to attendees of the 2017 and 2018 F.I.S.H. Workshops (approximately 40 and 100 attendees, respectively) and individuals who expressed interest in or registered for the
2019 Workshop. In addition, workshop steering committee members and participants were encouraged to share the survey link with other members of the fishing industry who might not have been targeted.

Survey participants were asked to rate the importance of each of the 30 knowledge-needs by selecting from a Likert-scale; 'not at all important,' 'slightly important,' 'moderately important,' 'very important,' 'extremely important,' or 'we already know enough about this question.' Specifically, we prefaced this section of the survey by informing participants that we would like "to understand the trawling engineering questions you would most like answered." In addition, four of the knowledge-needs included a set of follow-up questions to further refine our understanding of the participants' views (Table 1). At the end of the survey, participants were offered an opportunity to describe any other pertinent knowledge-needs not listed in the survey and were queried on basic demographic information.

Data were screened for partial responses (i.e., participants that did not enter fishery information or answer knowledgeneed questions), and quantitative values were assigned to each Likert-scale response as 'not at all important' $=0$, 'slightly important' = 1, 'moderately important' $=2$, 'very important' $=3$, and 'extremely important' $=4$. These scores were used to a) explore variation within and among fishery and industry groups in the perceived importance of knowledge-needs, and b) select the seven knowledge-needs based on the pre-workshop online survey for further focus during an in-person session held at the 2019 F.I.S.H. Workshop (Table 1 and Figure 1). For each knowledge-need, counts of 'we already know enough about this question' were used to gauge whether a knowledge-need was an appropriate candidate for the workshop. Given the

\section{Pre-Workshop Online Survey}

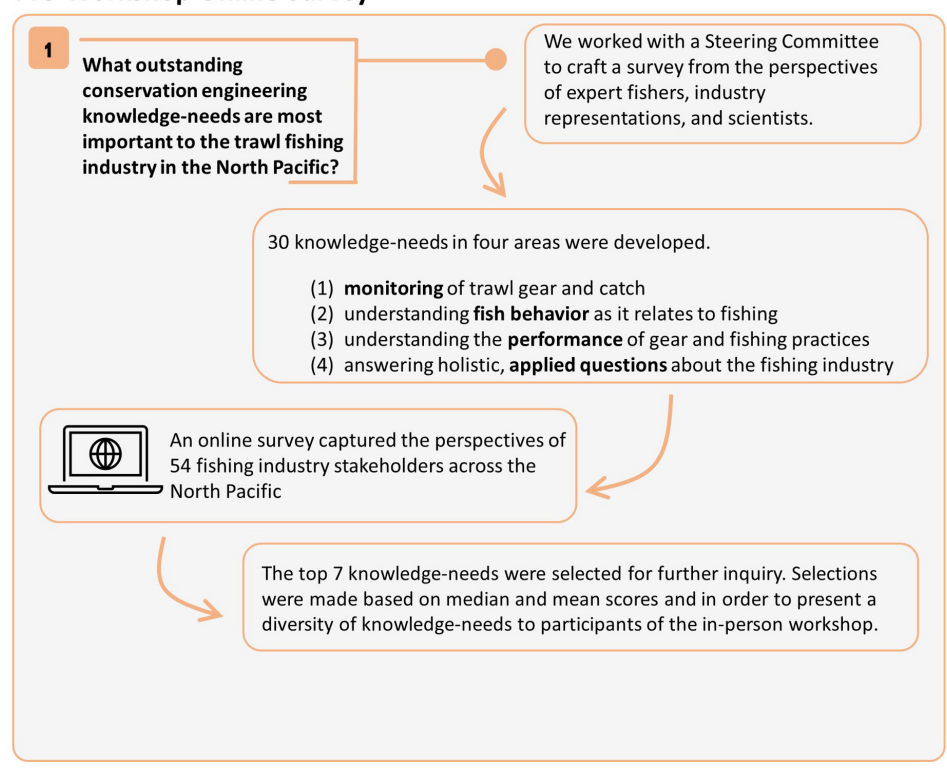

\section{In-Person Workshop}

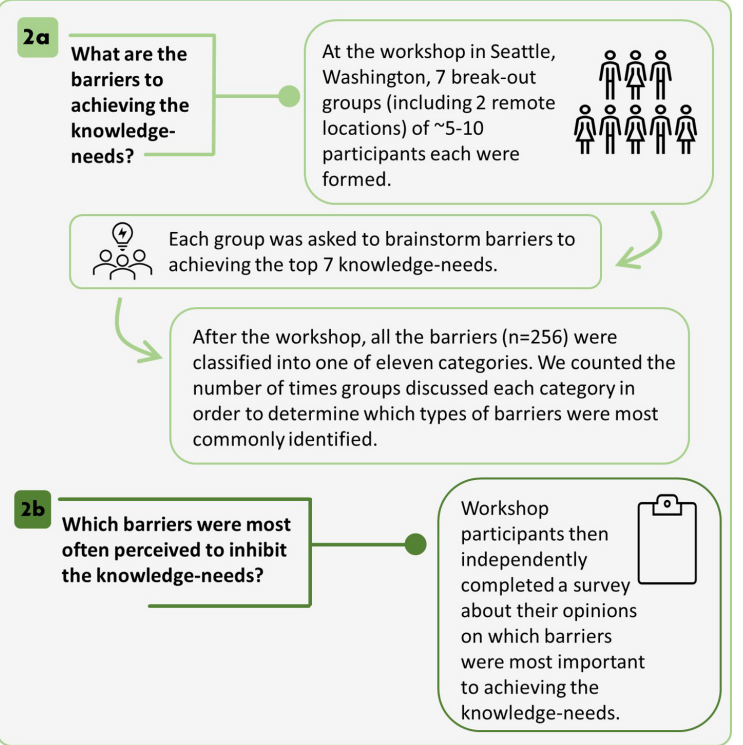

FIGURE 1 | Summary of primary study objectives and methods. The panel on the left represents methods used to generate a list of prioritized knowledge-needs using an online survey. The panel on the right represents methods used during the F.I.S.H. Workshop to collect information related to the barriers inhibiting progress in achieving top knowledge-needs. 


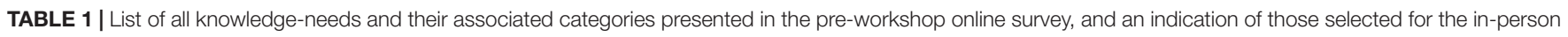
workshop ( ${ }^{*}$ knowledge-need was selected for the workshop; ${ }^{\star *}$ knowledge-need was selected for the workshop, but an additional series of questions helped refine the knowledge-need).

\begin{tabular}{ll}
\hline Category & Knowledge-need text \\
\hline Monitor & What is the abundance, weight, and size composition of the target \\
species catch? & What is the abundance, weight, and size composition of the non-target \\
Monitor & Whecies catch? \\
Monitor & What is the abundance, weight, and size composition of the excluded \\
Monitor & What is the abundance, weight, and size composition of the excluded \\
Monitor & What is the shape of the trawl under tow?
\end{tabular}

\begin{abstract}
Monitor What is the trawl's position relative to the seabed?
Monitor What is the shape of the trawl and position relative to the seabed in real-time (live)?

Monitor $\quad$ What is the catch and excluded catch in real-time (live)?

Behavior* What is the relationship between fish behavior and trawl-capture?
\end{abstract}

Behavior Are there non-contact stimuli (e.g., lasers, light, sound) that could herd fish and move them into a net that could replace conventional trawl components?

Behavior What is the target species' behavior in front of the trawl?

Behavior What is the target species' behavior in the trawl?

Behavior What is the non-target species behavior in front of the trawl?

Behavior What is the non-target species behavior in the trawl?

Performance $^{\star *}$ Is the gear doing what I want?

Performance What is the relationship between gear-seabed interactions and adverse impacts on benthic species?

Performance What effect does gear configuration have on fuel efficiency?

Performance What effect do fishing practices have on fuel efficiency?

Performance What effect does gear configuration have on target species catch rates (i.e., catch-per-unit-effort)?

Performance ${ }^{\star}$ What effect do fishing practices have on target species catch rates (i.e., catch-per-unit-effort)?

Performance $^{\star *}$ What effect does gear configuration have on non-target species avoidance?

Performance What effect do fishing practices have on non-target species avoidance?

Performance What effect does gear configuration have on gear damage and loss?

Performance What effect do fishing practices have on gear damage and loss?

Performance What effect does gear configuration have on safety?

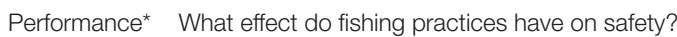

Applied $^{\star *} \quad$ Can a better understanding of monitoring gear, fish behavior, and/or gear performance information lead to improved fishery outcomes?

Applied How can information and data gathered by fishermen (e.g., video footage, temperature data, etc.) be made more useful for managers?

Applied How can we build and maintain healthy collaborations and trust between industry, scientists, and managers?

Applied How do trawl designs and operational practices influence the way industrialized fishing is perceived by the public in general?

\section{Additional questions}

How important is understanding the shape of the following trawl components while under tow? (a) doors, (b) ground-gear, (c) headrope, (d) footrope, (e) intermediate, (f) excluder, (g) cod-end

How important is understanding the following elements of fish behavior? (a) swimming (style, speed, endurance), (b) sensing (vision, smell, hearing), (c) response (diving, hiding, evading), (d) associations (solitary, schooling, species mixing)

How important is understanding the following aspects of gear performance? (a) fuel efficiency, (b) max target species catch-per-unit-effort (CPUE), (c) non-target species avoidance, (d) minimizing gear damage and loss, (e) safety
How important is achieving the following fishery outcomes? (a) catching the full target species allocation, (b) fewer fishery restrictions (closures, gear regulations, non-target catch limits), (c) increased profit (higher CPUE, reduced costs), (d) reduced risk (non-target catch limit flexibility, increased safety, lower regulatory uncertainty)

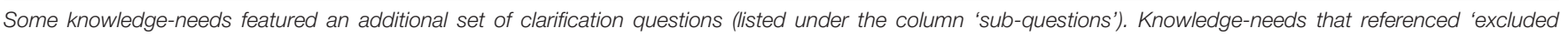
species' refer to fish that are directed away from the trawl using various techniques and bycatch reduction devices. 
non-normality of importance scores for the knowledge-needs, medians were the primary metrics (followed by mean score) used to help select the top-ranking items.

\section{Barriers to Knowledge-Needs}

Barriers to informing the top seven knowledge-needs ascertained from the pre-workshop survey were identified and characterized through in-person breakout groups and surveys at the F.I.S.H. Workshop at NOAA'S Alaska Fisheries Science Center in Seattle, WA, on December $17^{\text {th }}, 2019$ (Figure 1). Following a brief presentation on the research goals and instructions, workshop participants were separated into five breakout groups of 510 individuals. Participants selected their group, but were encouraged to sit with people they did not know. Those participating from the two satellite locations (Newport, Oregon and Kodiak, Alaska) formed groups locally and were connected through video conference.

Within each breakout group, a trained moderator from the research team facilitated a discussion in which group members were asked to identify potential barriers preventing further understanding of each of the seven top knowledge-needs. Up to ten barriers were discussed for each knowledge-need. Following the group discussions, each participant was given a paper survey that asked them to rate the degree to which each barrier identified by their group obstructs its respective knowledge-need. Answer options followed a Likert-scale, and responses were later quantified as 'not at all' $=0$, 'slightly' $=1$, 'moderately' $=2$, 'very' $=3$, to 'extremely' $=4$, or 'I don't know/does not apply to me.' Responses for 'I don't know/does not apply to me were tallied. In addition, the paper survey included two questions about the fisheries and industries in which they participate (e.g., Western Gulf of Alaska bottom trawl catcher vessel; Bering Sea/Aleutian Islands mid-water trawl catcher vessel (AFA), net company, researcher, etc.) and their role in these fisheries or industries (options included: chief executive officer, company owner/vessel owner, president/vice president, fleet manager, government affairs, vessel operations manager, business analyst/executive, compliance officer, chief engineer, engineer, primary vessel master/primary skipper, first mate/night skipper, relief skipper, factory manager, purser, deck boss, deck crew). Participants could make multiple selections for both questions and enter in text answers under an 'other' option.

After screening the survey data for errors (e.g., workshop attendees missed a barrier, entered a barrier not discussed by the group), all barriers discussed in the break-out groups $(n=256)$ were sorted into eleven categories created independently by three members of the research team. Two research team members independently assigned each barrier to a single category, and disagreements were resolved by a third team member. Barrier descriptions identified by break-out groups (i.e., before categorization by the research team) are also used to provide additional context when relevant.

To assess which barriers were identified most frequently during the workshop, two counts were performed; (1) The number of break-out groups (out of a total of 7) that discussed a barrier category for each knowledge-need (e.g., if a barrier category was discussed by 5 of 7 break-out groups for a particular knowledge-need, it was assigned a count of 5), and (2) The number of break-out groups in which an individual barrier category was discussed was aggregated across all knowledgeneeds. Barriers identified at the workshop were considered to have inherent importance as they were self-identified by workshop participants instead of ranking from a pre-identified list. Likert-scale scores representing the perceived strengths of barriers in preventing advancement toward addressing knowledge-needs were then assessed for areas of agreement and importance. Barriers were considered to have high agreement and importance if they had a minimum score of 2 (moderately preventative or greater) and a median score $\geq 3$ (very preventative or greater). Statistical tests were not performed between stakeholder groups, as participants could select multiple options for fishing attribute questions (e.g., in which fisheries they participate) such that we could not compare responses between distinct groups.

\section{RESULTS}

\section{Knowledge-Need Identification}

We received a total of 54 usable responses to the pre-workshop online survey (i.e., surveys were complete or near-complete). Participant demographics and attributes are detailed in Table 2. A complete list of knowledge-needs and associated scores identified in the survey can be found in Supplementary Table S1. In general, survey respondents identified knowledge-needs related to trawl gear performance as most important (Table 3). Four knowledge-needs with median scores of 4 were selected for inclusion at the in-person workshop. Three additional knowledge-needs, each with a median score of 3 and a high relative mean, were also selected for inclusion.

Given that four knowledge-needs were tied with median scores of 3 and mean scores of 3.3, conversations with the steering committee helped to refine the final selection to ensure their applicability to workshop participants and to select a manageable number of knowledge-needs to discuss during the workshop. There was low variance among different stakeholder groups, and no individual group believed a top knowledgeneed was of low importance (Supplementary Figure 1). This agreement suggested that the selected knowledge-needs were relevant across multiple stakeholder groups. Knowledge-needs with sub-categories (e.g., Is the gear doing what I want; Table 1) were further refined by sub-category, except for the knowledgeneed - What is the relationship between fish behavior and trawl-capture? In this case, summary statistics were similar across sub-categories, so all sub-categories were included in the final knowledge-need description for the workshop. Only four individuals identified knowledge-needs not listed in the survey.

\section{Barriers to Knowledge-Needs}

A total of 62 workshop attendees submitted usable responses to the workshop survey on barriers to the conservation engineering knowledge-needs. Participant demographics were generally similar between the pre-workshop online survey and workshop in-person survey (Table 2). However, more researchers 
TABLE 2 | Respondent demographics and fishery/industry groups for the pre-workshop online survey and during the in-person workshop.

\begin{tabular}{|c|c|c|}
\hline & $\begin{array}{l}\text { Pre-workshop online } \\
\text { survey (total } \\
\text { respondents }=54 \text { ) }\end{array}$ & $\begin{array}{c}\text { Workshop in-person } \\
\text { survey (total } \\
\text { respondents = 62) }\end{array}$ \\
\hline \multicolumn{3}{|l|}{ Gender } \\
\hline Female & 2 & 6 \\
\hline Male & 51 & 56 \\
\hline \multicolumn{3}{|l|}{ Fishery vessel } \\
\hline catcher-processor & 23 & 26 \\
\hline catcher-vessel & 28 & 34 \\
\hline Mothership & 8 & 10 \\
\hline \multicolumn{3}{|l|}{ Fishery region } \\
\hline BSAI & 43 & 38 \\
\hline central GOA & 21 & 23 \\
\hline western GOA & 14 & 19 \\
\hline other fishery & 6 & 9 \\
\hline \multicolumn{3}{|l|}{ Other } \\
\hline net company & 3 & 7 \\
\hline Researcher & 1 & 4 \\
\hline technology company & 3 & 11 \\
\hline trade association & 1 & 1 \\
\hline \multicolumn{3}{|l|}{ Role type } \\
\hline Boat & 34 & 23 \\
\hline Company & 22 & 16 \\
\hline Other & 8 & 28 \\
\hline
\end{tabular}

For demographic and attributes questions, survey participants were able to select multiple options, so column totals can sum to higher than the number of total participants. Stakeholders that did not work on-board vessels could still be classified as being associated with a particular fishery vessel or fishery region if they selected that they were associated with that fishery (e.g., a fishing company employee that represents specific vessel types, or a technology company engineer that works directly with vessels in specific fisheries).

and individuals associated with technology and trawl net manufacturing companies were present at the F.I.S.H Workshop than completed the online survey. This was expected as we aimed to focus knowledge-needs on the fishing industry's perspective.

During the workshop, 256 barriers were discussed and sorted into 11 categories (see Supplementary Materials for the complete list of barriers: barrier_data.csv). Barrier categories (with the number of times each category was discussed in break-out groups) were fishermen skill, experience, knowledge (39); regulations, management design (39); scientific knowledge, data gaps (36); technology (32); cost (28); vessel attributes, gear attributes, fishing attributes (24); fishermen behavior, communication (20); uncontrollable abiotic, biotic environmental/physical variables (14); economics (12); time (7); and impacts to fishermen (5) (Figure 2). Four barrier categories were identified as impeding all seven knowledgeneeds (technology; scientific knowledge, data gaps; fisherman skill, experience, knowledge; and cost); three barrier categories were identified as impeding six of the seven knowledge-needs (vessel attributes, gear attributes, fishing attributes; regulations, management design; and fishermen behavior, communication); and three barrier categories were identified as impeding five of the seven knowledge-needs (uncontrollable abiotic, biotic environmental/physical variables; time; and economics). Only one barrier category (impacts to fishermen) was identified as impeding less than five (2) of the seven knowledge-needs (Figure 2).

Exploration of Likert-scale scores representing the perceived strengths of barriers in preventing advancement toward addressing of knowledge-needs revealed several barriers that were, on average, perceived to be at least 'very' influential (median score $\geq 3$ and minimum score $\geq 2$ ). For example, all stakeholder groups reported median scores of 3 or higher for technology, cost, and fishermen behavior, communication as impediments to understanding how to maximize catch rates. Similarly, all stakeholder groups indicated that technology and fishermen skill, experience, knowledge are 'very' preventative in efforts to understand how to monitor catch and excluded catch in real-time. Finally, vessel attributes, gear attributes, fishing attributes were universally identified as important barriers to understanding the Safety knowledge-need. All barrier-by-knowledge-need combinations for each stakeholder group are presented in the Supplementary Materials (barriers_summary.csv).

\section{DISCUSSION}

We identified relevant knowledge-needs for conservation engineering innovation in North Pacific, United States trawl fisheries and barriers to addressing these knowledge-needs. These results provide direction for future initiatives that aim to achieve sustainability goals. While most knowledge-needs were perceived to hold at least moderate importance, we recommend that all listed knowledge-needs be considered viable research tracks, but with an emphasis on those identified as being of the highest relative importance. As such, we focus the following discussion on the top knowledge-needs and most important barriers, noting that significant overlap exists between many topics such that informing one knowledge-need may also aid in understanding another. Additionally, it is likely that changes in management and the environment, plus advancements in technology, could alter industry priorities, necessitating revisitation of knowledge-needs in the future.

\section{Fish Behavior: What Is the Relationship Between Fish Behavior and Trawl \\ Capture?}

Participants identified understanding fish behavior as it relates to trawl capture as an important knowledge-need, and all breakout groups identified scientific knowledge, data gaps as a barrier to informing this need (Figure 2). Knowledge about fish behavior (and differences among species) is essential to fishing success and improving fishing gear selectivity to avoid non-target species (Wardle, 1986; He, 2011). This necessitates greater knowledge of target versus non-target fish behavior. For example, innate differences in the herding behavior of compressiform (i.e., laterally compressed body) versus fusiform fishes (i.e., torpedo shaped body) have enabled trawl net designs that selectively catch fish with different body morphologies (Ryer, 2008). Catching and avoiding species with similar 


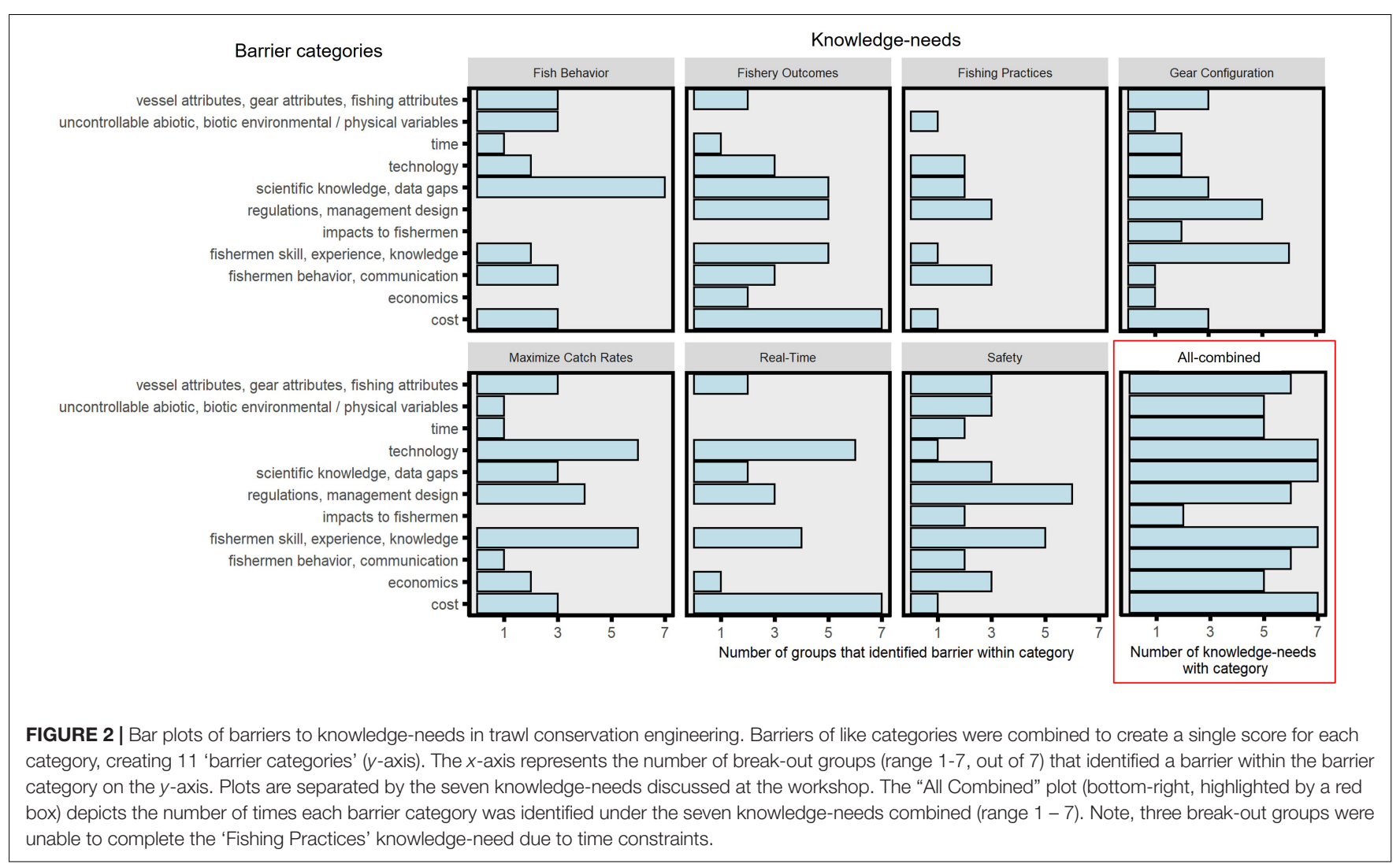

body morphology (e.g., when target and non-target fish are both compressiform; Lomeli et al., 2021) may necessitate a more sophisticated net design or approach that accounts for nuanced behavioral differences between the fish species. Addressing this knowledge-need requires collaborations among fishermen, researchers (e.g., physiologists, fish behaviorists), and the fishing/gear manufacturing industries to conduct applied research that is both scientifically robust and sufficiently applied (e.g., conducted under realistic fishing conditions) (Pol and Eayrs, 2021).

\section{Real-Time: What Is the Catch and Excluded Catch in Real-Time (Live)?}

Significant strides have been made over the last decade to capture imagery and video of trawl performance underwater, as is evidenced by the number of available 'off the shelf' camera systems and use of cameras in conservation engineering research and by the fishing industry (e.g., Noack et al., 2019; Sokolova et al., 2021). This includes advancements in wireless monitoring systems (e.g., Notus Electronics Ltd.) and in making camera units sufficiently rugged for use on trawl nets and allowing for live video streaming (e.g., Simrad FX80). Results of the workshop suggest that advancements in technology that allow for real-time awareness of gear performance and fish behavior would be highly sought-after and would similarly address other knowledge-needs around these topics. This was corroborated by a workshop break-out group that identified real-time information as a barrier to the knowledge-need
Fish behavior. However, a substantive impediment is the cost associated with purchasing, deploying, and maintaining the units that supply real-time information to the vessel's wheelhouse. All break-out groups identified cost as a barrier during the workshop. To date, real-time data comes at a high cost, in part due to the frequent use of a dedicated wire between the camera unit and wheelhouse in addition to the camera system. Costs associated with systems that provide real-time information (e.g., purchasing and deploying the hardware) and the requisite time investment (e.g., learning, troubleshooting, and maintenance) can be prohibitive for some vessels. Technological advancements are projected to reduce these costs, but we recommend that technology companies collaborate with fishermen across several diverse fisheries to ensure that fishermen can adopt new systems with different budgets and vessel constraints. We also highlight this as an opportunity for technology companies to partner with the fishing industry to capitalize on current advancements in technology to develop new innovative solutions.

\section{Maximize Catch Rates: Is the Gear Doing What I Want to Maximize Catch-Rates?}

Most pre-workshop online survey participants expressed the importance of understanding if their gear is doing what they want and prioritized understanding how their gear is performing to maximizing catch rates. Previous work with fishermen from two of the fisheries represented at the F.I.S.H. workshop suggested that the advancement of strategies and techniques to increase 
target catch (i.e., catch-per-unit-effort) has many benefits, such as increased profits, shorter fishing trips, and lowered fuel usage (Murphy et al., 2021). While these improvements clearly benefit the fishermen and fishing companies, more rapid fulfillment of harvest quotas would also likely result in less total benthic contact, which has been a focus of arguments for ecosystem-based management (Crowder et al., 2008), and reduced opportunities for interactions with non-target catch. Workshop results highlighted limitations in both technology and fishermen skill, experience, knowledge as being primary barriers (Figure 2). Again, the ability of fishermen to capture real-time information was explicitly identified in a break-out group as a barrier, here in relation to understanding how gear influences catch rates. The repeated mention of and focus on real-time technology confirmed that this should be a point of emphasis for future research and development. The suggestions around fishermen skill, experience, knowledge highlight the importance of inter-generational transmission of knowledge and training. During workshop break-out groups, several fishermen discussed the apparent decline in skill and knowledge over time, with younger fishermen lacking the expertise necessary to maintain high catch rates relative to those older or more experienced. Often coined the 'graying of the fleet', shifting demographics across many United States fisheries indicate a need for new training (by way of informal knowledge transfer and/or courses) and time at sea to help lessen the fishing learning curve for younger fishermen (Donkersloot and Carothers, 2016; Johnson and Mazur, 2018).

\section{Gear Configuration: What Effect Does Gear Configuration Have on Non-Target Species Avoidance?}

Similar to the knowledge-need maximize catch-rates, six out of seven breakout groups identified fishermen skill, experience, knowledge as limiting their ability to understand the effect of gear configuration on non-target species avoidance. Note that this barrier was discussed by at least one break-out group for all seven knowledge-needs, highlighting the value of maintaining skilled fishermen and mentoring newer fishermen in the operational and technical aspects of fishing. One potential strategy to address this barrier is to establish industry-driven training and workshops focused on elevating fishermen skills through peer learning and knowledge-sharing. These training sessions could be hosted or co-hosted by industry and academic partners. Currently, training sessions with commercial fishermen focus on safety protocols and best practices, which management agencies sometimes require (e.g., Lincoln and Conway, 1999; Casey et al., 2018). Our results demonstrate a need to expand the goals of training sessions to include knowledge and techniques for fishermen to harvest their catch efficiently, such as by manipulating gear configuration to improve non-target species avoidance and maximizing use of technology currently installed on the vessel or readily available. Training could be further supported by providing opportunities for fishermen to learn about gear design and use at a flume tank. Including both new entrants and experienced fishermen in these training sessions could foster the passage of information between generations of fishermen, potentially building inter-generational relationships that maintain essential knowledge and skills.

In five of seven break-out groups, barriers related to regulations and management design were identified as inhibiting the knowledge-need, Gear configuration. One break-out group summarized this barrier as "regulatory gear constraints" (e.g., mandated gear type or design) and another group as "regulatory process (e.g., exempted fishing permits) not in sync with fishing reality" (Supplementary materials; barrier_data.csv). These results suggest that dynamic fishing conditions (e.g., shifting species distributions), coupled with various gear restrictions, may create barriers for fishermen to avoid bycatch or develop new strategies under exempted fishing permits. Therefore, we recommend that research be conducted, such as via social science methods (e.g., Murphy et al., 2021), to characterize the tradeoffs associated with gear and other regulations to minimize the likelihood of unintended environmental consequences.

\section{Safety: What Effect Do Fishing Practices Have on Safety?}

In the pre-workshop online survey, fishery representatives agreed on the importance of further exploring the effects of fishing practices on safety. Consistently identified barriers included regulations, management design and fishermen skill, experience, knowledge. Previous research has also indicated that social factors, including the culture on-board fishing vessels, may contribute to the challenging nature of the uptake of new safety measures (Weil et al., 2016). While efforts have worked to reduce the race-to-fish through better fishing incentives such as fishery rationalization (e.g., allocation of catch shares; Hilborn, 2007), which involves various strategies to reduce the race-tofish, several break-out groups indicated that the race-to-fish (categorized under regulations, management design) still exists and is a primary barrier to improving safety. Others believed that requirements to discard non-target fish limited their ability to enhance safety by altering fishing practices (i.e., by reducing captain capacity to test new strategies for improving safety).

TABLE 3 | Finalized knowledge-needs for the in-person workshop and corresponding shortened names used throughout this manuscript.

\begin{tabular}{|c|c|}
\hline $\begin{array}{l}\text { Shortened } \\
\text { Name }\end{array}$ & Knowledge-Need Full Text \\
\hline Safety & What effect do fishing practices have on safety? \\
\hline $\begin{array}{l}\text { Fishery } \\
\text { Outcomes }\end{array}$ & $\begin{array}{l}\text { Can a better understanding of monitoring gear, fish } \\
\text { behavior, and/or gear performance information lead to } \\
\text { improved fishery outcomes, specifically related to catching } \\
\text { the full target species allocation? }\end{array}$ \\
\hline $\begin{array}{l}\text { Gear } \\
\text { Configuration }\end{array}$ & $\begin{array}{l}\text { What effect does gear configuration have on non-target } \\
\text { species avoidance? }\end{array}$ \\
\hline $\begin{array}{l}\text { Maximize Catch } \\
\text { Rates }\end{array}$ & Is the gear doing what I want to maximize catch-rates? \\
\hline Real-Time & What is the catch and excluded catch in real-time (live)? \\
\hline Fish Behavior & $\begin{array}{l}\text { What is the relationship between fish behavior and trawl } \\
\text { capture? }\end{array}$ \\
\hline $\begin{array}{l}\text { Fishing } \\
\text { Practices }\end{array}$ & $\begin{array}{l}\text { What effect do fishing practices have on target species } \\
\text { catch? }\end{array}$ \\
\hline
\end{tabular}


This is corroborated by other research where participants of the Bering Sea bottom trawl fleet in Alaska specified safety concerns associated with the process of discarding still-alive bycatch while on-deck (Murphy et al., 2021). This also highlights the importance of considering the effect on vessel safety when evaluating modifications to fishing gear or operations as a way to reduce bycatch or other incidental fishing impacts. In addition, similar to the discussion on Gear configuration, this is a topic that could be valuable to include in inter-generational discussions and training.

\section{Fishing Practices: What Effect Do Fishing Practices Have on Target Species Catch?}

Three break-out groups were unable to complete this knowledgeneed due to time constraints during the workshop and three of the remaining four groups discussed barriers in the categories regulations, management design, and fishermen behavior, communication. Again, the race-to-fish was mentioned and under the barrier fishermen behavior, communication, several groups discussed the competitiveness and lack of communication among fishermen. Collectively, these findings suggest that intrafishery competition still exists despite efforts to rationalize and reduce derby-style fishing through catch-share programs for many United States fisheries (Birkenbach et al., 2017). Another break-out group highlighted that some fishermen are "resistant to change," thereby inhibiting achievement of the fishing practices knowledge-need. The willingness of fishermen to change behavior is an important factor contributing to an individual's adaptive capacity to changes in the fishery (Marshall and Marshall, 2007). Moreover, our results support the notion that efforts to improve the resilience of fisheries should consider the psychological and behavioral aspects of affecting positive change. In addition, this suggests that competition can be a motivating factor to incentivize change.

\section{Fishery Outcomes: Can a Better Understanding of Monitoring Gear, Fish Behavior, and/or Gear Performance Information Lead to Improved Fishery Outcomes?}

Prioritization of the comprehensive knowledge-need, Fishery outcomes, demonstrates the integrated nature of the other knowledge-needs identified by our study. As a result, efforts to overcome barriers for one knowledge-need may effectively facilitate a better understanding of other knowledge-needs as well. For example, workshops to train newer fishermen could lead to improved fishery outcomes, enhance safety, and help fishermen better configure their gear to avoid nontarget species (knowledge-needs; Fishery outcomes, Safety, Gear configuration, respectively).

\section{CONCLUSION}

By fostering active and collaborative discussion among fisheries stakeholders, this study identified top knowledge-needs and barriers to implementing conservation technologies and practices in trawl fishing in the North Pacific, United States. The top knowledge-needs (Table 3) reflect what we would expect: fishermen want to catch more fish and fish more efficiently, and that meeting conservation goals will require an understanding of how fishermen perceive the tradeoffs associated with improving sustainability versus catch efficiency (not that they are mutually exclusive). Overcoming barriers to addressing these knowledge-needs and, ultimately, implementing practical solutions to meet large-scale sustainability goals will require shared knowledge and responsibility. An important caveat to these findings, however, is that closing knowledge gaps does not guarantee progress toward or uptake of sustainable solutions, nor does it mean we cannot or should not continue to improve upon current strategies. The ultimate actions and decisions of fishermen and fishery managers may be influenced by exogenous political factors, for instance, or psychological and attitudinal variables that alter the perceived benefits and costs of implementing particular conservation engineering strategies (Ajzen, 1991). We aim to increase ultimate uptake of conservation engineering solutions by highlighting knowledge-needs and barriers that were identified by the end user, fishermen.

Based on our results, we recommend collaborative efforts to remove barriers to address the top knowledge-needs that include fishermen, company representatives, managers, researchers, and technical experts. We also highlight the importance of inter-generational knowledge transfer in the fishing industry, the timely opportunity for technology developers, and the importance of evaluating the role of regulations and safety when developing conservation engineering solutions. Similarly, additional investigation is needed to better understand the voluntary adoption and economics of conservation engineering. Finally, while this study was focused regionally and by gear type, we feel that the lessons learned can be applied more generally in considering how to capitalize on conservation engineering tools and resources and move forward in innovation for the betterment of global fisheries.

\section{DATA AVAILABILITY STATEMENT}

The original contributions presented in the study are included in the article/Supplementary Material, further inquiries can be directed to the corresponding author/s.

\section{ETHICS STATEMENT}

The studies involving human participants were reviewed and approved by Alaska Pacific University Institutional Review Board. Written informed consent for participation was not required for this study in accordance with the national legislation and the institutional requirements. Note, both studies provided an informed consent document but did not require a participant signature. 


\section{AUTHOR CONTRIBUTIONS}

$\mathrm{RM}, \mathrm{NY}, \mathrm{NW}, \mathrm{AK}$, and $\mathrm{BH}$ contributed to the design and execution of the study and contributed to revising and writing the manuscript. RM analyzed the data and wrote the original draft of the manuscript. All authors contributed to the article and approved the submitted version.

\section{FUNDING}

Funding was provided by donations provided by the Pollock Conservation Cooperative and the Groundfish Forum through the Alaska Education Tax Credit Program (Alaska Statute 43.20.014).

\section{ACKNOWLEDGMENTS}

We thank the facilitators of the F.I.S.H. workshop and the logistic/technology support who helped the day run smoothly; specifically, Andrew Gorbonos, Doug Hayes, Frank Kikuchi, Cory Lescher, Chris Magel, Troy Martin, John Olson, and Scott

\section{REFERENCES}

Ajzen, I. (1991). The theory of planned behavior. Organ. Behav. Hum. Decis. Process. 50, 179-211. doi: 10.1016/0749-5978(91)90020-T

Althaus, F., Williams, A., Schlacher, T., Kloser, R., Green, M., Barker, B., et al. (2009). Impacts of bottom trawling on deep-coral ecosystems of seamounts are long-lasting. Mar. Ecol. Prog. Ser. 397, 279-294. doi: 10.3354/meps08248

Armstrong, M., Payne, A., Deas, B., and Catchpole, T. (2013). Involving stakeholders in the commissioning and implementation of fishery science projects: experiences from the UK Fisheries Science Partnershipa. J. Fish Biol. 83, 974-996. doi: 10.1111/jfb.12178

Berkes, F. (2009). Evolution of co-management: role of knowledge generation, bridging organizations and social learning. J. Environ. Manag. 90, 1692-1702. doi: 10.1016/j.jenvman.2008.12.001

Birkenbach, A. M., Kaczan, D. J., and Smith, M. D. (2017). Catch shares slow the race to fish. Nature 544, 223-226. doi: 10.1038/nature21728

Brewer, D., Rawlinson, N., Eayrs, S., and Burridge, C. (1998). An assessment of bycatch reduction devices in a tropical Australian prawn trawl fishery. Fish. Res. 36, 195-215. doi: 10.1016/s0165-7836(98)00096-4

Broadhurst, M., Sterling, D., and Millar, R. (2015). Modifying otter boards to reduce bottom contact: effects on catches and efficiencies of triple-rigged penaeid trawls. Fish. Manag. Ecol. 22, 407-418. doi: 10.1111/fme.12140

Casey, T. W., Krauss, A. D., and Turner, N. (2018). The one that got away: lessons learned from the evaluation of a safety training intervention in the Australian prawn fishing industry. Saf. Sci. 108, 218-224. doi: 10.1016/j.ssci.2017. 08.002

Catchpole, T. L., and Gray, T. S. (2010). Reducing discards of fish at sea: a review of European pilot projects. J. Environ. Manag. 91, 717-723. doi: 10.1016/j. jenvman.2009.09.035

Clark, M. R., Althaus, F., Schlacher, T. A., Williams, A., Bowden, D. A., and Rowden, A. A. (2016). The impacts of deep-sea fisheries on benthic communities: a review. ICES J. Mar. Sci. 73, i51-i69. doi: 10.1093/icesjms/fsv123

Crowder, L. B., Hazen, E. L., Avissar, N., Bjorkland, R., Latanich, C., and Ogburn, M. B. (2008). The impacts of fisheries on marine ecosystems and the transition to ecosystem-based management. Annu. Rev. Ecol. Evol. Syst. 39, 259-278. doi: 10.1146/annurev.ecolsys.39.110707.173406

Cunningham, S., Bennear, L. S., and Smith, M. D. (2016). Spillovers in regional fisheries management: do catch shares cause leakage? Land Econ. 92, 344-362. doi: $10.3368 /$ le.92.2.344
Smeltz. We are very grateful for the guidance and expertise of the Steering Committee, who collectively helped make this research applied and meaningful to conservation engineering: Julie Bonney, Taunette Dixon, Austin Estabrooks, John Gauvin, John Gruver, Katherine Hellen-Schneider, Katy McGauley, and Sara Skamser. We would also like to thank our colleagues that reviewed this manuscript and provided helpful feedback, including Henry Milliken and Lekelia Jenkins. We appreciate the two reviewers, Jordan Feekings and Stephen Eayrs, whose feedback significantly improved our manuscript. The scientific results and conclusions, as well as any views or opinions expressed herein, are those of the authors and do not necessarily reflect those of NOAA or the US Department of Commerce. Reference to trade names does not imply endorsement by the National Marine Fisheries Service, NOAA.

\section{SUPPLEMENTARY MATERIAL}

The Supplementary Material for this article can be found online at: https://www.frontiersin.org/articles/10.3389/fmars. 2022.800176/full\#supplementary-material

Decker, D. J., Krueger, C. C., Baer, R. A. Jr., Knuth, B. A., and Richmond, M. E. (1996). From clients to stakeholders: a philosophical shift for fish and wildlife management. Hum. Dimen. Wildl. 1, 70-82. doi: 10.1080/108712096093 59053

Donkersloot, R., and Carothers, C. (2016). The graying of the Alaskan fishing fleet. Environ. Sci. Policy Sustain. Dev. 58, 30-42. doi: 10.1080/00139157.2016. 1162011

Eayrs, S., and Pol, M. (2019). The myth of voluntary uptake of proven fishing gear: investigations into the challenges inspiring change in fisheries. ICES J. Mar. Sci. 76, 392-401. doi: 10.1093/icesjms/fsy178

Feekings, J., O’Neill, F. G., Krag, L., Ulrich, C., and Veiga Malta, T. (2019). An evaluation of European initiatives established to encourage industry-led development of selective fishing gears. Fish. Manag. Ecol. 26, 650-660. doi: $10.1111 /$ fme. 12379

Finkbeiner, E. M., Wallace, B. P., Moore, J. E., Lewison, R. L., Crowder, L. B., and Read, A. J. (2011). Cumulative estimates of sea turtle bycatch and mortality in USA fisheries between 1990 and 2007. Biol. Conserv. 144, 2719-2727. doi: 10.1016/j.biocon.2011.07.033

Food and Agriculture Organization [FAO] (2020). The state of world fisheries and aquaculture 2020. Sustainability in action. Rome: Food and Agriculture Organization

Grabowski, J. H., Bachman, M., Demarest, C., Eayrs, S., Harris, B. P., Malkoski, V., et al. (2014). Assessing the vulnerability of marine benthos to fishing gear impacts. Rev. Fish. Sci. Aquac. 22, 142-155. doi: 10.1080/10641262.2013.846292

He, P. (2011). Behavior of marine fishes: capture processes and conservation challenges. Hoboken: John Wiley \& Sons. doi: 10.1002/9780813810966

Hegger, D., and Dieperink, C. (2014). Toward successful joint knowledge production for climate change adaptation: lessons from six regional projects in the Netherlands. Ecol. Soc. 19:34. doi: 10.5751/ES-06453-190234

Hilborn, R. (2007). Moving to sustainability by learning from successful fisheries. AMBIO J. Hum. Environ. 36, 296-303. doi: 10.1579/0044-7447(2007)36[296: mtsblf]2.0.co;2

Hutchings, P. (1990). Review of the effects of trawling on macrobenthic epifaunal communities. Mar. Freshw. Res. 41, 111-120. doi: 10.1071/MF9900111

Johnson, T. R., and Mazur, M. D. (2018). A mixed method approach to understanding the graying of Maine's lobster fleet. Bull. Mar. Sci. 94, 1185-1199. doi: 10.5343/bms.2017.1108

Kaiser, M. J., Hilborn, R., Jennings, S., Amaroso, R., Andersen, M., Balliet, K., et al. (2016). Prioritization of knowledge-needs to achieve best practices for 
bottom trawling in relation to seabed habitats. Fish Fish. 17, 637-663. doi: $10.1111 /$ faf. 12134

Kennelly, S. J. (1995). The issue of bycatch in Australia's demersal trawl fisheries. Rev. Fish Biol. Fish. 5, 213-234. doi: 10.1007/BF00179757

Lincoln, J. M., and Conway, G. A. (1999). Preventing commercial fishing deaths in Alaska. Occup. Environ. Med. 56, 691-695. doi: 10.1136/oem.56.10.691

Lomeli, M. J. M., Wakefield, W. W., Herrmann, B., Dykstra, C., Simeon, A., Rudy, D., et al. (2021). Use of artificial illumination to reduce pacific halibut bycatch in a U.S. West Coast groundfish bottom trawl. Fish. Res. 233:105737. doi: 10.1016/j.fishres.2020.105737

Marshall, N., and Marshall, P. (2007). Conceptualizing and operationalizing social resilience within commercial fisheries in northern Australia. Ecol. Soc. 12:1. doi: 10.5751/ES-01940-120101

Murphy, R. Jr., Estabrooks, A., Gauvin, J., Gray, S., Kroska, A. C., Wolf, N., et al. (2021). Using mental models to quantify linear and non-linear relationships in complex fishery systems. Mar. Policy 132:104695. doi: 10.1016/j.marpol.2021. 104695

Noack, T., Stepputtis, D., Madsen, N., Wieland, K., Haase, S., and Krag, L. A. (2019). Gear performance and catch process of a commercial Danish anchor seine. Fish. Res. 211, 204-211. doi: 10.1016/j.fishres.2018.11.012

Pauly, D., Zeller, D., and Palomares, M. L. D. (eds) (2020). Sea Around Us Concepts, Design and Data. Available Online at: https://www.seaaroundus.org/data/\#/ global? chart=catch - chart \&dimension=gear\&measure=tonnage $\&$ limit $=10$ (accessed January 16, 2022).

Pol, M., and Eayrs, S. (2021). Behaviour in a bottom trawl: moving forward to limit catches of Atlantic cod. ICES J. Mar. Sci. 78, 2317-2324. doi: 10.1093/icesjms/ fsab106

Ryer, C. H. (2008). A review of flatfish behavior relative to trawls. Fish. Res. 90, 138-146. doi: 10.1016/j.fishres.2007.10.005

Sokolova, M., Mompó Alepuz, A., Thompson, F., Mariani, P., Galeazzi, R., and Krag, L. A. (2021). A Deep Learning Approach to Assist Sustainability of Demersal Trawling Operations. Sustainability 13:12362. doi: 10.3390/ su132212362
Stram, D. L., and Ianelli, J. N. (2015). Evaluating the efficacy of salmon bycatch measures using fishery-dependent data. ICES J. Mar. Sci. 72, 1173-1180. doi: 10.1093/icesjms/fsul68

Wardle, C. (1986). "Fish behaviour and fishing gear," in The Behaviour of Teleost Fishes, ed. T. J. Pitcher (Boston, MA: Springer), 463-495. doi: 10.1007/978-14684-8261-4_18

Weil, R., Pinto, K., Lincoln, J., Hall-Arber, M., and Sorensen, J. (2016). The use of personal flotation devices in the Northeast lobster fishing industry: an examination of the decision-making process. Am. J. Ind. Med. 59, 73-80. doi: 10.1002/ajim.22537

Wilberg, M. J., Ihde, T. F., Secor, D. H., and Miller, T. J. (2009). "FishSmart: a stakeholder-centered approach to improve fisheries conservation and management," in International Council for Exploration of the Sea, ICES CM 2009/O15, (Berlin, German: ICES).

Yochum, N., Starr, R. M., and Wendt, D. E. (2011). Utilizing fishermen knowledge and expertise: keys to success for collaborative fisheries research. Fisheries 36, 593-605. doi: 10.1080/03632415.2011.633467

Conflict of Interest: The authors declare that the research was conducted in the absence of any commercial or financial relationships that could be construed as a potential conflict of interest.

Publisher's Note: All claims expressed in this article are solely those of the authors and do not necessarily represent those of their affiliated organizations, or those of the publisher, the editors and the reviewers. Any product that may be evaluated in this article, or claim that may be made by its manufacturer, is not guaranteed or endorsed by the publisher.

Copyright $\odot 2022$ Murphy, Yochum, Wolf, Kroska and Harris. This is an open-access article distributed under the terms of the Creative Commons Attribution License (CC BY). The use, distribution or reproduction in other forums is permitted, provided the original author(s) and the copyright owner(s) are credited and that the original publication in this journal is cited, in accordance with accepted academic practice. No use, distribution or reproduction is permitted which does not comply with these terms. 